\title{
Cost-Effectiveness Analysis for Arsenic Water Supply Project in Bangladesh
}

\author{
Nikhil Chandra Shil \\ Senior Lecturer \\ Department of Business Administration \\ East West University \\ 43, Mohakhali Commercial Area, Dhaka - 1212 \\ Bangladesh \\ E-mail: nikhilacc@yahoo.com
}

\begin{abstract}
Cost-effectiveness analysis $(C E A)$ is widely used to assess the investment criteria where cost-benefit analysis (CBA) is not economically feasible to apply. $C B A$ is generally used where there is a commercial motive whereas $C E A$ is used where service motive is prioritized. Thus, it is mainly applicable to evaluate social projects where the beneficiaries are scattered in any area or the society at large. The paper works as a background paper highlighting those issues with greater detail so that a stranger can use the tool confidently. The steps required for such application and the potential areas where $C E A$ will produce significant results are also highlighted here to limit the scope of the paper. The methodology used here is basically descriptive to keep it simple and easy to comprehend, with the practical insights of using such tool in a real life social project. The use of CEA is outlined here in a World Bank funded Arsenic Water Supply Project in Bangladesh.
\end{abstract}

Keywords: Cost-effectiveness analysis, Cost-benefit analysis, Arsenic Water Supply Project, Bangladesh

\section{Introduction}

Cost-effectiveness analysis refers to the consideration of decision alternatives in which both their costs and consequences are taken into account in a systematic way. It is a decision-oriented tool, in that it is designed to ascertain which means of attaining particular goals are most efficient. Consider two strategies intended to lengthen life in patients with heart diseases. One is simple and cheap (e. g., aspirin and $\beta$-blockers); the other is more complex, more expensive, and more effective (e. g., medication plus cardiac catheterization, angioplasty, stents, and bypass). Now, which strategy will be more effective? CEA will help to take decision in such situation.

In evaluating alternatives three different variants of analysis is available, viz. cost effectiveness analysis, cost utility analysis and cost benefit analysis. In $C E A$ the benefits are expressed in numeric but non-monetary terms, say, life years gained or symptom-free days whereas in cost-utility analysis they are expressed as quality-adjusted-life-years $(Q A L Y s)$ and in cost-benefit analysis in monetary terms. As with all economic evaluation techniques, the aim of $C E A$ is to maximize the level of benefits relative to resources available. The main metric is a ratio whose denominator represents project outcome in numerical but non-monetary unit, and numerator represents costs in monetary terms. The result can be interpreted as a unit cost, such as cost per kilometer or passenger, cost per child vaccinated or cost per laborer trained. Thus $C E A$ is used to assess the projects that have similar outcome but way of doing and other factors are different. The lower the unit cost, the more effective the project is.

CEA was developed in the 1950s by the United States Department of Defense as a device for adjudicating among the demands of the various branches of the armed services for increasingly costly weapons systems with different levels of performance and overlapping missions (Hitch and McKean, 1960). By 1960s it had become widely used as a tool for analyzing the efficiency of alternative government programs outside the military. It was first applied to health care in the mid-1960s and was introduced with enthusiasm to clinicians by Weinstein and Stasson in 1977: If these approaches were to become widely understood and accepted by the key decision makers in the health-care sector, including the physician, important health benefits or cost savings might be realized. CEA has also been used to determine which drugs will be reimbursed by public agencies in both Australia and the Canadian province of Ontario (Drummond et al., 1997; Sloan and Conover, 1995). 
The paper targets to explicate CEA with its basics and usability under budget constraints. And the discussion is mainly based on different secondary sources like research papers, published journal papers, books etc. Different interventions and ingredients with cost data is generated from a World Bank document titled "Project appraisal document for a proposed credit in the amount of SDR 24.2 million equivalents to the People's Republic of Bangladesh for an arsenic mitigation water supply project" upon permission. CEA is formulated mathematically at the very beginning followed by a discussion on the techniques of assessing the costs and benefits. Later on different interventions are introduced with the simulation of selective the most effective one under fund constraint. Finally, the paper concludes with an explanation of decision rule for selecting the candidates participated in the study and rationality behind it.

\section{Cost Effectiveness Analysis: Formulation and Derivation}

As an offshoot of $C B A, C E A$ is developed in economics to address resource allocation issues. Though $C B A$ is well grounded in welfare economics, $C E A$ is based on no such solid foundation. $C E A$ has become popular in cases where full-fledged $C B A$ is either too difficult to apply, or alternatively, where $C B A$ is judged inappropriate. Although $C E A$ is intuitive and easy to apply, it posses a number of methodological issues that are not always understood by practitioners (Hildred and Watkins, 1996). The discussion on the formulation of CEA can be started with the following basic equation:

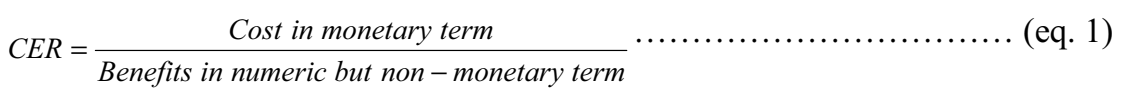

$C E R$ in equation 1 represents cost effectiveness ratio. Numerator represents total cost of the project in monetary terms throughout its life ( $\mathrm{t}$ ); and denominator represents benefits expressed in numerical but non-monetary term. Cost may be initial (investment) or recurring (running). Initial cost (cost at $t=0$ ) requires no discounting but recurrent cost requires and for these two separate cost, we may use one single notation, e. g., Cost $t_{t}=\sum_{t=0}^{n} \frac{C_{t}}{(1+i)^{t}}$ where $i$ stands for a suitable discount rate. The denominator of the equation refers to the benefit from the project and presented in numerical but non-monetary terms. Let's suppose that the benefits are denoted by capital $\mathrm{n}(\mathrm{N})$ and to make it comparable with costs, let's again suppose that it will also be generated throughout the life and discounted by a suitable rate as used in case of costs. Thus the notion of the denominator will be, Benefit $t_{t}=\sum_{t=1}^{n} \frac{N_{t}}{(1+i)^{t}}$. Now, equation 1 can be extended with the notion of costs and benefits as given in equation 2 .

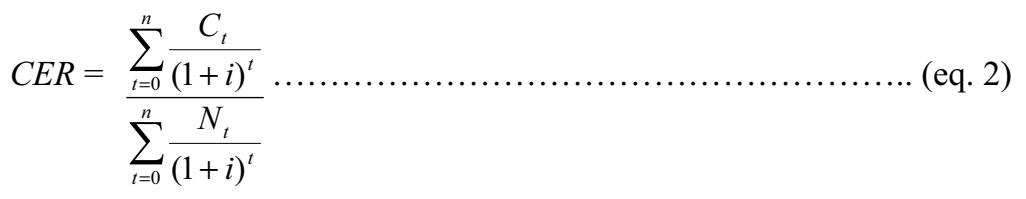

But, the basic formula of $C B A$ incorporates costs and benefits in a different way as presented below in equation 3:

$N P V=\sum_{t=0}^{n} \frac{\left(B_{t}-C_{t}\right)}{(1+i)^{t}}$

Where, $N P V$ represents net present value, $B_{t}$ represents benefits in year $t$ and $C_{t}$ costs in year $t$ and $i$ is the discount rate.

Thus, the basic difference between these two equations is in terms of incorporation of benefits into consideration. As in $C B A$ both costs and benefits are expressed in monetary terms, they can be used to calculate the difference (net value) but in case of $C E A$ this is not possible and for that reason it is a ratio. In most of the projects that are headed towards the social welfare, or otherwise, the beneficiaries are scattered in the society in such a way that no monetary value can be put to quantify the benefits, $C E A$ is more applicable and accurate to use. For example, let's take the World Bank Project on Arsenic Mitigation Water Supply, where the beneficiaries are the targeted people living in the targeted area under the project. It's really difficult to quantify the benefits in monetary terms. But the outflow of fund is very much explicit even with the sources and that's why $C E A$ is very much effective to evaluate such a project. Table 1 calculates CER per person based on the project data using the equations derived earlier.

\section{Insert Table 1}

Here, the project sanctioning authority now may take decision on the basis of cost per person to evaluate the effectiveness of the project, or whether there are some other projects that will be more effective than the current one.

Many evaluations are confined to a relatively short time period of a year or less, and estimates of outcomes and costs are confined to that period. Yet, many evaluations occur over two or more years. When that is the case, outcomes and costs that occur in the future should be appropriately discounted to their "present value." Both $C B A$ and $C E A$ use 
discounting to express future costs and benefits in equivalent units of a base year. The purpose of this procedure is to reflect the desirability of receiving outcomes sooner (or, similarly, incurring costs later). To calculate present value, one uses the following general formula:

$$
P V=\sum_{t=0}^{n} \frac{O_{t}}{(1+r)^{t}}
$$

where $O_{t}$ is the outcome occurring at time $t$, and $r$ is a discount rate between 0 and 1 (the same formula applies to discounting costs). For example, the present value of a benefit of $\$ 100$ that is received immediately (at $t=0)$ is $\$ 100$. If the same amount is received one year hence, and the discount rate is $0.05(5 \%)$, the present value is $\$ 95.24(100 / 1.05)$; in two years, it is $\$ 90.70\left(100 / 1.05^{2}\right)$. Thus, outcomes occurring farther in the future are discounted more steeply. A discount rate larger than 0.05 would imply that future outcomes are to be discounted even more heavily. Intuitively, this implies that individuals evince an even stronger preference for outcomes that occur immediately.

There are two interrelated points in the discussion. What should the discount rate express? And should we discount benefits and costs in the $C E R$ at the same rate? To start with the first point, the reasons for discounting costs and benefits in $C B A$ or $C E A$ are inflation, risk, the opportunity cost of capital and social time preference. The first two points hold insignificant relevance with our area of discussion and hence, we can dismiss them entirely. In $C E A$, current cost is the best measure and we can use inflation corrected discount rate to check inflation. To control risk, there are a lot of ways available that are smarter and effective from discount rate like probability, sensitivity analysis, simulation etc. The opportunity cost of capital means the cost due to sacrificing the option to invest the fund in other alternatives. If that alternative has earned a rate of return of, say, $10 \%$, then it stands to reason that the project under consideration must have at least the same rate of return to be justified. If the project has a positive NPV at this discount rate at this discount rate, it is apt to go for the project. Discounting in $C E A$ is recommended for exactly the same reason. Social time preference reflects the value the decision maker attaches to consumption benefits through time. If benefits are expressed in money terms, diminishing marginal utility of money makes that one-dollar of consumption for a rich person is worth less than one dollar for a poor person. To the extent that future generations are supposed to be better of materially, it is justified to discount the monetary values they assign to benefits. This argument can be used to discount benefits in $C B A$. If health benefits are expressed in physical terms, as is the case in $C E A$, the decision maker is likewise entitled to discount future benefits if he esteems that future patients have access to better health services than present patients, and that for this reason additional health treatments allocated to them are less desirable than those accruing to present patients. The argument is basically about equity. If future generations are better off, either financially or in terms of health services, there should be a preference for granting additional health benefits to the present generation. An appropriate discount rate expresses this. Social time preference discount rates can be estimated, as long as one is prepared to make a value judgment about intergenerational equity. Most calculations suggest that the social time preference discount rate is lower than the opportunity cost of capital discount rate.

Which of those two considerations, the opportunity cost of capital, or social time preference, is more relevant? There is no satisfactory answer to this, except to say that both must be addressed. The problem is that we have only one discount rate, and we cannot use it to express both at the same time. Satisfactory solutions have been worked out to deal with this problem. For instance, in UNIDO (1972) the discount rate expresses social time preference, and the opportunity cost of capital argument is taken into consideration by calculating a shadow price of investment. The alternative solution, proposed in Little and Mirrlees (1974), and taken over in Squire and van der Tak (1975), is to discount at the opportunity cost of capital and to use a shadow price for the value of consumption to take care of the social time preference dimension. Both approaches are equivalent, as discussed in Berlage and Renard (1985). Unfortunately those sophisticated but rigorous approaches to $C B A$ have not been popular in practice, and now a days both theoreticians and practitioners tend to stick to a single discount rate. This has severely hampered the debate about discounting in $C E A$. Viscusi (1995) for instance, fails to discuss these issues at all. Katz and Welch (1993) provide a more nuance analysis in which they acknowledge the issue raised here. But in the end they argue in favor of using a single discount rate. But this is far from evident. Health projects typically cause both a change in the time pattern of investment over time, and in the time pattern of health benefits.

In dealing with two contending discount rates, $C E A$ has an edge over $C B A$. Whereas $C B A$ cannot easily handle more than one discount rate, $C E A$ can do so without a problem, as physical benefits are in the denominator of the cost effectiveness ratio whereas costs are measured in the numerator. There is no reason why we would have to apply the same discount rate to both. We suggest replacing equation (2) with

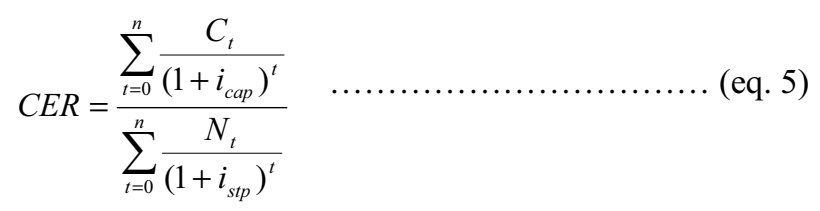


Where:

$\mathrm{i}_{\text {cap }}$ : discount rate expressing the opportunity cost of capital

$i_{\text {stp }}$ : discount rate expressing social time preference for consumption

The choice of discount rate is somewhat arbitrary, although a plausible range is between three and seven percent (Barnett, 1996). A recent set of national guidelines for economic evaluation of health care programs recommends a discount rate of three percent, although they also recommend the calculation of present values under a wider range of assumptions about the discount rate (Lipscomb et. al, 1996). The task force of experts organized by the U.S. Public Health Service $(P H S)$ has also recommended using a discount rate of $3 \%$ to reflect the lower economic value of an expense that is delayed and the higher value of a benefit that is recognized sooner (Gold et al., 1996). In part, the ambiguity stems from different conceptual approaches that can be used to arrive at a discount rate. Boardman et al. (1996) provide a general discussion. For a discussion of discounting that is applied specifically to non-pecuniary outcomes, see Drummond et al. (1997), Keeler \& Cretin (1983), Levin \& McEwan (2000) and Viscusi (1995).

\section{Measuring Cost-effectiveness}

The successful use of $C E A$ requires the estimation of costs and effectiveness accurately. This section is devoted to different criteria that are important for assessment of cost and effectiveness.

\subsection{Assessing cost}

Costs are seen differently from different points of view. In economics the notion of cost is based on the value that would be gained from using resources elsewhere - referred to as the opportunity cost. It is usual, in practice, to assume that the price paid reflects the opportunity cost and to adopt a pragmatic approach to costing and use market prices wherever possible. But this only rigorous cost study, that is based on the economic concept of opportunity cost, is now three decades old (Bartell, 1968). In CEA it is conventional to distinguish between the direct costs and the indirect costs associated with the intervention, together with what are termed intangibles. Intangibles may be difficult to quantify, still, sometimes they may have significant consequences on the interventions and should be included in the cost profile. A typical cost profile of the project under consideration is given in Table 2.

Insert Table 2 here

It is essential to specify exclusion and inclusion of specific costs categories in a $C E A$ to ensure that the findings are not subject to misinterpretation. Both $C B A$ and $C E A$ can be used from different points of view, ranging from the individual to group to society at large. When $C E A$ is used for healthcare as we are considering here, the later perspective is the appropriate one. Thus, we limit our attention to this case here. In this case, costs incurred by health sector are obvious candidates. In addition, future health costs in added years of life should also be counted here (Johannesson and Meltzer, 1998; Meltzer, 1997). Indeed, there is no reason to exclude any opportunity cost that emerges from a careful with-without analysis in case of $C B A$ and before-after analysis in case of $C E A$ (Figure 1). Non-medical costs; like patients' cost of transport to health centers, the value of time spent undergoing health treatment, the value of efforts given or hassle consumed to avail the facility of treatment; must also be counted. In fact, when the societal perspective comes, the net of costs should be as wide as possible as the total of societal costs from every respect should be considered. If we have no qualms with a broad definition of costs, and in fact argue in its favor, we must at the same time be attentive to the consequences of all inclusive cost measures for the interpretation of the cost-effectiveness ratio.

Insert Figure 1 here

Cost analysis is not always incorporated in decision-making. There are, however, some notable exceptions to this rule, many of these in health-care. In the United States, the state of Oregon attempted to use a wide-ranging cost-utility analysis to rank medical interventions and determine which would be available to Medicaid recipients (Eddy, 1991). Eventually, political considerations led to substantial modifications and the cost-utility approach "[was] ultimately abandoned in favor of a hybrid process in which cost was not a major factor in determining the final rankings" (Sloan and Conover, 1995). The World Bank used a series of cost analyses to formulate health sector lending priorities for developing countries (Jamison et al., 1993; World Bank Report, 1993).

Drummond et al. (1997) provides a more comprehensive quality checklist for cost analysis studies in health-care, covering both outcomes and costs. An important question is whether the cost analysis literature adheres to these minimal standards. The sheer quantity of cost analysis in health-care has led several authors to review costing methods. The results are sobering for research consumers. Among 77 cost effectiveness and cost-benefit studies that were reviewed, Udvarhelyi et al. (1992) found that $52 \%$ failed to properly discount costs, $47 \%$ failed to report cost-benefit or cost-effectiveness ratios, and $70 \%$ did not conduct a sensitivity analysis. In a review of 51 health cost-utility analyses, Gerard (1992) found that $69 \%$ included a comprehensive set of ingredients, $63 \%$ percent provided a clear description of methods used to cost ingredients, and $61 \%$ clearly described the costing data. Just $37 \%$ of studies conducted an extensive sensitivity analysis. Gerard concludes that about half the studies should be deemed "limited" in their execution. 
In cost analysis a simple technique is considered to ascertain the cost of an intervention in terms of the value of the resources that were used or lost by applying them in one way rather than in another. To do this, a straightforward approach called the "ingredients" method is used widely.

The ingredients method relies upon the notion that every intervention uses ingredients that have a value or cost (Levin, 1975, 1988, 1995; Levin \& McEwan, 2000). If specific ingredients can be identified and their costs can be ascertained, we can estimate the total costs of the intervention as well as the cost per unit of effectiveness. The ingredients method to cost estimation entails three distinct phases: (a) identification of ingredients; (b) determination of the value or cost of the ingredients and the overall costs of an intervention; and (c) an analysis of costs in an appropriate decision-oriented framework.

The first step is to ascertain which ingredients are required for an intervention (Levin, 1983). This entails the determination of what ingredients are required to create or replicate the interventions that are being evaluated, casting as wide a net as possible. It is obvious that even contributed or donated resources such as volunteers must be included as ingredients according to such an approach, for such resources will contribute to the outcome of the intervention, even if they are not included in budgetary expenditures.

There are three overriding considerations that should be recognized in identifying and specifying ingredients. First, the ingredients should be specified in sufficient detail that their value could be ascertained in the next stage of the analysis. Second, the categories into which ingredients are placed should be consistent, but there is no single approach to categorization that will be suitable in all cases. Finally, the degree of specificity and accuracy in listing ingredients should depend upon their overall contribution to the total cost of the intervention. It is important to obtain a familiarity with the intervention that is being subjected to cost analysis. Only by doing so can the evaluators identify the ingredients used by the intervention in sufficient detail (and, subsequently, attach values to those ingredients). Normally this familiarity can be gained in at least three ways: (1) through a review of program documents, (2) through discussions with individuals involved in the intervention, and (3) through direct observation of the interventions. If we consider the example of the World Bank Project on "Arsenic Mitigation Water Supply", we get the interventions, its ingredients with analysis of costs as given in Table 3.

Insert Table 3 here

\subsection{Assessing Effectiveness}

Before starting the cost analysis, it is necessary to know what the decision problem is, how to measure effectiveness, which alternatives are being considered and what their effects are. If a problem has arisen on the policy agenda that requires a response, a careful understanding of the problem is crucial to addressing its solution (Levin, 1983). Once the problem has been formulated, it will be necessary to consider how to assess the effectiveness of alternatives. For this purpose, clear dimensions and measures of effectiveness will be needed. Table 4 shows examples of effectiveness measures that respond to particular program objectives.

Insert Table 4 here

Given the problem and criteria for assessing the effectiveness of proposed solutions, it is necessary to formulate alternative programs or interventions. The search for such interventions should be as wide-ranging and creative as possible. This procedure sets the stage for the evaluation of effectiveness of the alternatives, a process that is akin to the standard use of evaluation methods (Rossi \& Freeman, 1985). Estimates of effectiveness can be derived from previous evaluations or from tailored evaluations for the present purpose.

It is important to emphasize that the evaluation of effectiveness is separable from the evaluation of costs. Most standard evaluation designs for assessing the effectiveness of an intervention are also suitable for incorporation into cost-effectiveness studies. This can be found in the standard evaluation literature (Rossi \& Freeman, 1985; Cook \& Campbell, 1979). The cost analysis is not typically found in the general evaluation literature and has been developed independently as a sub-specialization (Levin, 1983).

\section{Architecture of Using Cost Effectiveness Analysis}

The forgoing discussion concludes that identification of interventions in social project is very much important. A distinction must be made between those interventions that are completely independent $-i$. e., where the costs and effects of one intervention are not affected by other interventions - and those that are mutually exclusive - i. e., where implementing one intervention means that another cannot be implemented, or where the implementation of one intervention results in changes to the costs and effects of another.

\subsection{Independent interventions}

Using CEA with independent interventions requires that cost-effectiveness ratios (CERs) are calculated for each intervention and placed in rank order by using equation 4 below that is modified from equation 1 : 


$$
\left.C E R=\frac{\text { Costs of Intervention }}{\text { Health Effects } \text { Produced (say, life }- \text { years gained })} \ldots \ldots \ldots \ldots \ldots \text { (eq. } 4\right)
$$

For example, in table 5, there are three interventions for different patient groups, with the alternative for each of them of 'doing nothing'. According to $C E A$, intervention B should

Insert Table 5 here

be given priority over A since it has a lower $C E R$, but in order to decide which intervention to implement, the extent of resources available must be considered (table 6 ).

Insert Table 6 here

If a further intervention becomes available, it should be considered on the basis of its CER figure compared with table 4 . Resources for the new intervention should be considered in the same manner as above.

\subsection{Mutually exclusive interventions}

In reality, the likelihood is that choices will have to be made between different treatment regimens for the same condition, different dosages or treatment versus prophylaxis - i. e., mutually exclusive interventions. In this situation, incremental cost-effectiveness ratios (ICERs) are used:

$$
I C E R=\frac{\text { Difference in } \cos t \text { s between int erventions }(I 1 \text { and I2) }}{\text { Difference in health effects between int erventions }(I 1 \text { and I2) }} \ldots \ldots . . . . . \text { (eq. 5) }
$$

The alternative interventions are ranked according to their effectiveness - on the basis of securing maximum effect rather than considering cost - and ICERs are calculated as shown in Table 7.

Insert Table 7 here

The least effective intervention (I1) has the same average CER as its ICER, because it is compared with the alternative of 'doing nothing'. The negative ICER for I2 means that by adopting I2 rather than I1 there is an improvement in life years gained and a reduction in costs. The ICER for I3 works out to be 187.5 , which means that it costs $\$ 187.5$ to generate each additional life-year gained compared with I2. Alternatives that are more expensive and less effective are excluded. From table 7, we find that interventions I2 and I4 are followed by interventions I1 and I3 that are costly and therefore needed to be excluded. The table 8 is redrawn by excluding these two more expensive and less effective interventions.

\section{Insert Table 8 here}

Now the question of identification of 'dominated' alternative comes. Here, I4 is dominated by $\mathrm{I} 2$ since the former is more effective and costs less to produce an additional unit of effect (\$62.5 compared with \$85.71). The dominated alternative is then excluded and the ICERs are recalculated again in table 9.

Insert Table 9 here

Finally, interventions I2 and I5 are proved to be cost effective. In deciding between them, the size of the available budget must be brought to consider. If the available budget is $\$ 100000$, all patients should receive intervention I1, while, if the available budget is $\$ 190000$, all patients should receive the more effective intervention I5. However, if the budget is, say, $\$ 130000$, then, since the cost difference between I2 and I5 is $\$ 90000$ and the budget surplus is $\$ 30000$, it is possible to switch one-third of patients to I5 and still remain within budget.

\section{Conclusion}

$C E A$ is used as a ranking tool where a lot of alternatives become candidates to a limited budget. Rather in some situation, decision based on solely monetary consideration is proved unethical and illogical. Let's consider the example as we have taken here. Whenever the question of sound health comes, the expenditure or willingness to pay depends on the amount of income. So, if we consider the societal perspective, we have to initiate such project that will be cost effective in the sense that most people will avail the benefit at a lower amount of cost. Thus, in most of the social projects, $C E A$ can be used as a ranking tool to decide which alternative(s) to be chosen. But much use of $C E A$ leads to use of $C B A$. Even when we are talking about budget, we are going for $C B A$ ultimately. $C B A$ is a commercial perspective to choose the alternatives. In $C B A$, no projects may be chosen due to their infeasibility on financial perspective. But, in this case also, $C E A$ ranks one alternative to be the best among other. Basically, as $C E A$ is an offshoot of $C B A$, a detailed $C E A$ ultimately leads to $C B A$. But, when the beneficiary becomes the society, we should go for $C E A$ that is ethical and logical as it ensures the effective use of resources for the benefit of overall society.

\section{References}

Barnett, W. S. (1996). Lives in the balance: Age-27 benefit-cost analysis of the High/Scope Perry Preschool Program. Ypsilanti, MI: High/Scope Press. 
Bartell, E. (1968). Costs and benefits of Catholic elementary and secondary schools. Notre Dame: Notre Dame Press. Berlage, L. \& Renard, R. (1985). The Discount Rate in Cost-Benefit Analysis and the Choice of a Numeraire. Oxford Economic Papers, 691-699.

Boardman, A. E., Greenberg, D. H., Vining, A. R., \& Weimer, D. L. (1996). Cost-benefit analysis: Concepts and practice. Upper Saddle River, NJ: Prentice Hall.

Cook, T. D. \& Campbell, D. T. (1979). Quasi-Experimentation. Houghton Mifflin, Boston, Massachusetts.

Drummond, M. F., O'Brien, B., Stoddart, G. L. and Torrance, G. W. (1997). Methods for the economic evaluation of health care programs. Oxford: Oxford University Press.

Eddy, D. M. (1991). Oregon's methods: Did cost-effectiveness analysis fail? Journal of the American Medical Association, 266(15), 2135-2141.

Gerard, K. (1992). Cost-utility in practice: A policy maker's guide to the state of the art. Health Policy, 21, $249-279$.

Gold, M. R., Siegel, J. E., Russell, L. B., \& Weinstein, M.C. (1996). Cost-Effectiveness in Health and Medicine. New York: Oxford University Press, 285.

Hildred, W. and Watkins, L. (1996). The nearly Good, the Bad, and the Ugly in Cost-Effectiveness Analysis in Health Care. Journal of Economic Issues, 30(3).

Hitch, J. C. and McKean, N. R. (1960). The Economics of Defense in the Nuclear Age. Harvard University Press, Cambridge, Massachusetts.

Jamison, D. T., Mosley, W. H., Measham, A. R., and Bobadilla, J. L. (eds.) (1993). Disease control priorities in developing countries. Oxford: Oxford University Press.

Johannesson, M. and Meltzer, D. (1998). Some Reflections on Cost-Effectiveness Analysis. Health Economics, 7, 1-7.

Katz, D. A. \& Welch, H. G. (1993). Discounting in Cost-Effectiveness Analysis on Healthcare Programmes. PharmacoEconomics, 3(4), 276-285.

Keeler, E. B., \& Cretin, S. (1983). Discounting of life-saving and other non-monetary Effects. Management Science, 29, 300-306.

Levin, H. M. (1975). Cost-effectiveness in evaluation research, in M. Guttentag and E. Struening (eds.), Handbook of evaluation research, 2, Beverly Hills, CA: Sage Publications.

Levin, H. M. (1983). Cost-Effectiveness: A Primer. Beverly Hills, CA: Sage Publications.

Levin, H. M. (1988). Cost-effectiveness and educational policy. Educational Evaluation and Policy Analysis, 10(1), 51-69.

Levin, H. M. (1995). Cost-effectiveness analysis, in M. Carnoy (ed.), International encyclopedia of economics of education, Oxford: Pergamon, 381-386.

Levin, H. M. \& McEwan, P. J. (2000). Cost-effectiveness analysis: Methods and applications. Thousand Oaks, CA: Sage Publications.

Lipscomb, J., Weinstein, M. C. \& Torrance, G. W. (1996). Time preference, in M. R. Gold, L. B. Russell, J. E. Siegel, \& M. C. Weinstein (eds.), Cost-effectiveness in health and medicine, New York: Oxford University Press, 214-246.

Little, I. M. D. \& Mirrlees, J. A. (1974). Project Appraisal and Planning in Developing countries. Heinemann: London. Meltzer, D. (1997). Accounting for future costs in Medical Cost-Effectiveness Analysis. Journal of Health Economics, 16(1), 33-64.

Rossi, P. H. \& Freeman, H. E. (1985). Evaluation: A Systematic Approach. Beverly Hills, CA: Sage Publications.

Sloan, F. A. and Conover, C. J., 1995, The use of cost-effectiveness/cost-benefit analysis in actual decision making: Current status and prospects. In F. A. Sloan (ed.), Valuing health care: Costs, benefits, and effectiveness of pharmaceuticals and other medical technologies. Cambridge: Cambridge University Press.

Squire, L. \& van der Tak, H.G. (1975). Economic Analysis of Projects. Johns Hopkins University Press.

Udvarhelyi, I. S., Colditz, G. A., Rai, A., \& Epstein, A. M. (1992). Cost-effectiveness and cost-benefit analyses in the medical literature: Are the methods being used correctly? Annals of Internal Medicine, 116, 238-244.

UNIDO. (1972). Guidelines for Project Evaluation. New York: United Nations.

Viscusi, W. K. (1995). Discounting health effects for medical decisions, in F. A. Sloan (ed.), Valuing health care: Costs, benefits, and effectiveness of pharmaceuticals and other medical technologies, Cambridge: Cambridge University Press, 125-147.

World Bank. (1993). World development report 1993: Investing in health. New York: Oxford University Press. 
Table 1. Project Costs and Benefits

\begin{tabular}{|l|l|r|r|r|r|r|}
\hline \multicolumn{1}{|c|}{ Particulars } & Rules & $\mathbf{9 8 / 9 9}$ & $\mathbf{9 9 / 0 0}$ & $\mathbf{0 0 / 0 1}$ & $\mathbf{0 1 / 0 2}$ & Total \\
\hline $\begin{array}{l}\text { 1. Project Costs (in million US\$, with } \\
\text { base year 1998): }\end{array}$ & & & & & \\
\hline 1.1 Investment & & 8.3 & 10.9 & 17.3 & 4.9 & 41.4 \\
\hline 1.2 Recurrent & & 0.7 & 0.7 & 0.8 & 0.8 & 3.0 \\
\hline $\begin{array}{l}\text { 2. Total Present Value @ 12\% (the rate as } \\
\text { used in the project) }\end{array}$ & $1.1+1.2$ & 9.0 & 11.6 & 18.1 & 5.7 & 44.4 \\
\hline 4. Project Benefits (in numbers) & 8.925 & 10.29 & 15.20 & 4.296 & 38.71 \\
\hline 5.Population served (average) & & & & & & \\
\hline 6. Discounted @ 12\% & & & & & & \\
\hline 7. CER (cost per person) & $3 \div 6$ & \multicolumn{7}{|c|}{$\$ 2.55$} \\
\hline
\end{tabular}

Table 2.Cost Profile of the Project

\begin{tabular}{|l|l|l|}
\hline 1.0 Direct Costs: \\
\hline & 1.1 Medical : & drugs, staff time, equipment \\
\hline & 1.2 Patient $\quad:$ & Transport, out-of-pocket expenses \\
\hline 2.0 Indirect Costs: Production losses, other uses of time \\
\hline 3.0 Intangibles: Pain, suffering, adverse effects \\
\hline
\end{tabular}


Table 3. Estimated Project Costs in million US\$

\begin{tabular}{|c|c|c|c|c|}
\hline \multirow{2}{*}{$\begin{array}{c}\text { Interventions/ } \\
\text { Alternative } \\
\text { Programs }\end{array}$} & \multirow{2}{*}{ Ingredients } & \multicolumn{3}{|c|}{ Cost Analysis } \\
\hline & & Local & Foreign & Total \\
\hline \multirow{10}{*}{$\begin{array}{l}\text { On - Site } \\
\text { Mitigation }\end{array}$} & 1. Provide emergency/temporary water supply. & & & \\
\hline & & 7.3 & 0.1 & 7.4 \\
\hline & 2. Participatory appraisal of subprojects & 1.7 & - & 1.7 \\
\hline & 3. Establish sustainable rural systems & & & \\
\hline & Community development & 5.2 & - & 5.2 \\
\hline & Design and construction & 6.5 & - & 6.5 \\
\hline & 4. Establish sustainable urban systems & & & \\
\hline & Institutional development & 0.6 & - & 0.6 \\
\hline & Design and construction & 4.3 & - & 4.3 \\
\hline & $\begin{array}{l}\text { 5. Provide limited health relief for arsenic } \\
\text {-affected patients }\end{array}$ & 0.2 & 0.2 & 0.4 \\
\hline \multicolumn{2}{|c|}{ Subtotal On-Site Mitigation } & 25.8 & 0.3 & 26.1 \\
\hline \multirow{5}{*}{$\begin{array}{l}\text { Understanding } \\
\text { of the Arsenic } \\
\text { Problem }\end{array}$} & $\begin{array}{l}\text { 1. Undertake well screening and community } \\
\text { understanding. }\end{array}$ & 2.5 & - & 2.5 \\
\hline & 2. Studies & & & \\
\hline & Causes and impacts & 0.2 & 0.2 & 0.4 \\
\hline & Social and economic approaches & 0.1 & 0.1 & 0.2 \\
\hline & Groundwater prospecting & 0.3 & 0.4 & 0.7 \\
\hline \multicolumn{2}{|c|}{ Subtotal Understanding of the Arsenic Problem } & 3.1 & 0.7 & 3.8 \\
\hline \multirow{7}{*}{$\begin{array}{l}\text { Institutional } \\
\text { Strengthening }\end{array}$} & 1. Support project management & 3.3 & 2.3 & 5.6 \\
\hline & $\begin{array}{l}\text { 2. Establish capacity for data collection, } \\
\text { management and dissemination }\end{array}$ & 2.4 & 1.6 & 4.0 \\
\hline & $\begin{array}{l}\text { 3. Establish capacity for technical and social } \\
\text { assessment of options }\end{array}$ & 0.4 & 0.4 & 0.8 \\
\hline & 4. Training of NGOs & - & 0.2 & 0.2 \\
\hline & $\begin{array}{l}\text { 5. Capacity building for central and local } \\
\text { government officials }\end{array}$ & 1.5 & 0.5 & 2.0 \\
\hline & 6. Strengthen policy and institutional reform & 0.5 & 0.4 & 0.9 \\
\hline & 7. Enhance community development & 0.5 & 0.5 & 1.0 \\
\hline \multicolumn{2}{|c|}{ Subtotal Institutional Strengthening } & 8.6 & 5.9 & 14.5 \\
\hline \multicolumn{2}{|l|}{ Total } & 37.5 & 6.9 & 44.4 \\
\hline
\end{tabular}


Table 4. Examples of Effectiveness Measures

\begin{tabular}{|l|l|}
\hline Program Objectives & Measure of Effectiveness \\
\hline Program completions & Number of beneficiaries receiving the benefits \\
\hline $\begin{array}{l}\text { Reduce morbidity and } \\
\text { mortality }\end{array}$ & Number of people suffering from arsenicosis \\
\hline Ensure sound health & Percentage changes in life years gained \\
\hline Ensure pure water supply & $\begin{array}{l}\text { Number of people availing the pure water as compared with the number } \\
\text { of people availed pure water before the project. }\end{array}$ \\
\hline Poverty alleviation & Cost saved by the people due to their less or no visit to the physician. \\
\hline Societal development & Changes in the life style of the targeted people. \\
\hline Education & $\begin{array}{l}\text { Number of people trained under the project to handle arsenic related } \\
\text { problem by themselves or with the help of others. }\end{array}$ \\
\hline Employment & Number of people got employed in the project. \\
\hline Economic Development & $\begin{array}{l}\text { Impact of the project on the Gross National Product (GNP), Inflation, } \\
\text { Productivity, Per Capita Income and other macro economic variables }\end{array}$ \\
\hline
\end{tabular}

Table 5. Cost-effectiveness of three independent interventions

\begin{tabular}{cccc}
\hline Interventions & $\begin{array}{c}\text { Cost (\$) } \\
{[\mathbf{C}]}\end{array}$ & $\begin{array}{c}\text { Health Effect } \\
\text { (life-years gained) }[\mathbf{E}]\end{array}$ & $\begin{array}{c}\text { Cost-effectiveness ratio } \\
\text { (\$/life-years gained) }[\mathbf{C} / \mathbf{E}]\end{array}$ \\
\hline $\mathrm{B}$ & 300000 & 3800 & 78.95 \\
$\mathrm{~A}$ & 200000 & 2500 & 80.00 \\
$\mathrm{C}$ & 250000 & 2600 & 96.15 \\
\hline
\end{tabular}

Table 6. Budget-Interventions Trade-off

\begin{aligned} \hline Budgets available (\$) & Intervention(s) to be implemented \\ \hline $\mathbf{3 0 0 ~ 0 0 0} &$ As much of intervention B as budget allows \\ $\mathbf{=} \mathbf{3 0 0 0 0 0} &$ All of intervention B \\ $\mathbf{3 0 0 0 0 0}-\mathbf{5 0 0 0 0 0} &$ All of intervention B and as much of A as budget allows \\ $=\mathbf{5 0 0 0 0 0} &$ All of interventions B and A \\ $\mathbf{5 0 0 ~ 0 0 0}-\mathbf{7 5 0 0 0 0} &$ All of interventions B and A and as much of C as budget allows \\ $=\mathbf{7 5 0 0 0 0} &$ All 3 interventions \end{aligned}


Table 7. Incremental cost effectiveness ratios

\begin{tabular}{cccccc}
\hline Intervention & $\begin{array}{c}\text { Costs }(\$) \\
{[\mathbf{C}]}\end{array}$ & $\begin{array}{c}\text { Effects (life-years } \\
\text { gained) }[\mathbf{E}]\end{array}$ & $\begin{array}{c}\text { Incremental } \\
\text { cost }[\Delta \mathbf{C}]\end{array}$ & $\begin{array}{c}\text { Incremental } \\
\text { Effect }[\Delta \mathbf{E}]\end{array}$ & $\begin{array}{c}\text { ICER } \\
{[\Delta \mathbf{C} / \Delta \mathbf{E}]}\end{array}$ \\
\hline $\mathbf{I 1}$ & 150000 & 1500 & 150000 & 1500 & 100 \\
$\mathbf{I 2}$ & 100000 & 1600 & -50000 & 100 & -500 \\
$\mathbf{I 3}$ & 175000 & 2000 & 75000 & 400 & 187.5 \\
$\mathbf{I 4}$ & 160000 & 2300 & -15000 & 300 & -50 \\
$\mathbf{I 5}$ & 190000 & 2800 & 30000 & 500 & 60 \\
\hline
\end{tabular}

Table 8. Exclusion of more costly and less effective alternatives

\begin{tabular}{cccccc}
\hline Intervention & $\begin{array}{c}\text { Costs }(\$) \\
{[\mathbf{C}]}\end{array}$ & $\begin{array}{c}\text { Effects (life-years } \\
\text { gained) }[\mathbf{E}]\end{array}$ & $\begin{array}{c}\text { Incremental } \\
\text { cost }[\Delta \mathbf{C}]\end{array}$ & $\begin{array}{c}\text { Incremental } \\
\text { Effect }[\Delta \mathbf{E}]\end{array}$ & $\begin{array}{c}\text { ICER } \\
{[\Delta \mathbf{C} / \Delta \mathbf{E}]}\end{array}$ \\
\hline $\mathbf{I 2}$ & 100000 & 1600 & 100000 & 1600 & 62.5 \\
$\mathbf{I 4}$ & 160000 & 2300 & 60000 & 700 & 85.71 \\
$\mathbf{I 5}$ & 190000 & 2800 & 30000 & 500 & 60 \\
\hline
\end{tabular}

Table 9. Exclusion of dominated alternatives

\begin{tabular}{cccccc}
\hline Intervention & $\begin{array}{c}\text { Costs }(\$) \\
{[\mathbf{C}]}\end{array}$ & $\begin{array}{c}\text { Effects (life-years } \\
\text { gained) }[\mathbf{E}]\end{array}$ & $\begin{array}{c}\text { Incremental } \\
\text { cost }[\Delta \mathbf{C}]\end{array}$ & $\begin{array}{c}\text { Incremental } \\
\text { Effect }[\Delta \mathbf{E}]\end{array}$ & $\begin{array}{c}\text { ICER } \\
{[\Delta \mathbf{C} / \Delta \mathbf{E}]}\end{array}$ \\
\hline $\mathbf{I 2}$ & 100000 & 1600 & 100000 & 1600 & 62.5 \\
$\mathbf{I 5}$ & 190000 & 2800 & 90000 & 1200 & 75 \\
\hline
\end{tabular}

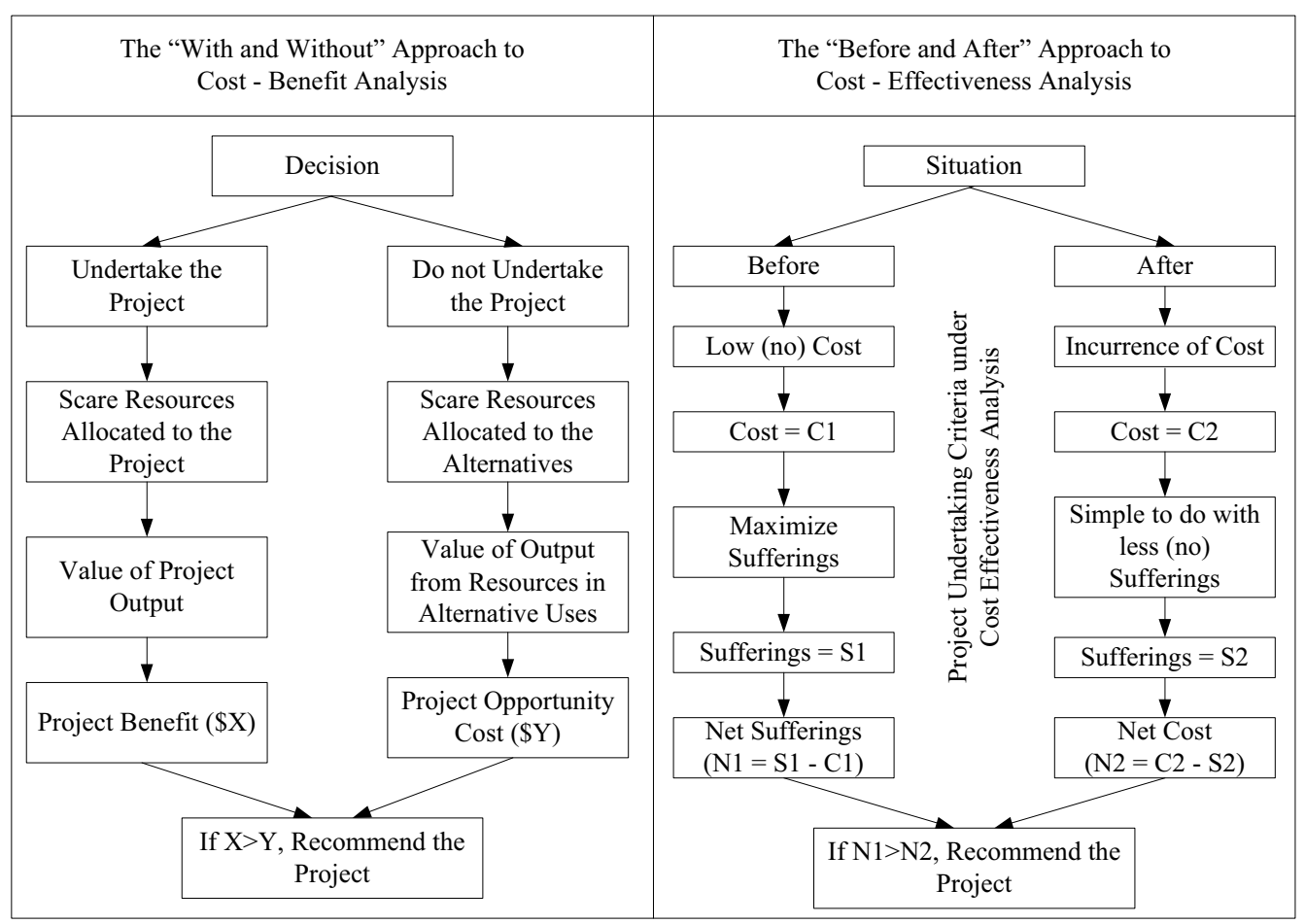

Figure 1: Decision Rule Comparison 